NATIONAL LABORATORY

MANAGED BY UT-BATTELLE

FOR THE DEPARTMENT OF ENERGY

\title{
Developing Load Cell Monitoring on the Mock UF 6 Feed and Withdrawal System
}

\section{February 2013}

\section{Prepared by}

Ross Snow Jim Garner Michael Whitaker

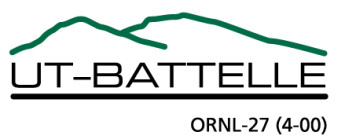




\section{DOCUMENT AVAILABILITY}

Reports produced after January 1, 1996, are generally available free via the U.S. Department of Energy (DOE) Information Bridge.

Web site http://www.osti.gov/bridge

Reports produced before January 1, 1996, may be purchased by members of the public from the following source.

National Technical Information Service

5285 Port Royal Road

Springfield, VA 22161

Telephone 703-605-6000 (1-800-553-6847)

TDD 703-487-4639

Fax 703-605-6900

E-mail info@ntis.gov

Web site http://www.ntis.gov/support/ordernowabout.htm

Reports are available to DOE employees, DOE contractors, Energy Technology Data Exchange (ETDE) representatives, and International Nuclear Information System (INIS) representatives from the following source.

Office of Scientific and Technical Information

P.O. Box 62

Oak Ridge, TN 37831

Telephone 865-576-8401

Fax 865-576-5728

E-mail reports@osti.gov

Web site http://www.osti.gov/contact.html

This report was prepared as an account of work sponsored by an agency of the United States Government. Neither the United States Government nor any agency thereof, nor any of their employees, makes any warranty, express or implied, or assumes any legal liability or responsibility for the accuracy, completeness, or usefulness of any information, apparatus, product, or process disclosed, or represents that its use would not infringe privately owned rights. Reference herein to any specific commercial product, process, or service by trade name, trademark, manufacturer, or otherwise, does not necessarily constitute or imply its endorsement, recommendation, or favoring by the United States Government or any agency thereof. The views and opinions of authors expressed herein do not necessarily state or reflect those of the United States Government or any agency thereof. 
Nuclear Security and Isotope Technology Division

\title{
DEVELOPING LOAD CELL MONITORING ON THE MOCK UF 6 FEED AND WITHDRAWAL SYSTEM
}

\author{
Ross Snow \\ Jim Garner \\ Michael Whitaker
}

Date Published: February 2013

Prepared by

OAK RIDGE NATIONAL LABORATORY

Oak Ridge, Tennessee 37831-6283

managed by

UT-BATTELLE, LLC

for the

U.S. DEPARTMENT OF ENERGY

under contract DE-AC05-00OR22725 



\section{CONTENTS}

Page

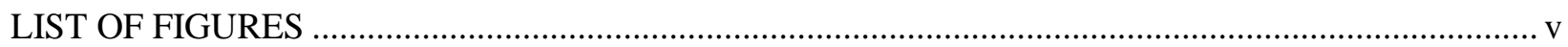

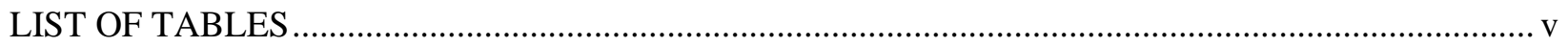

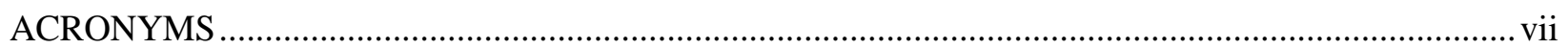

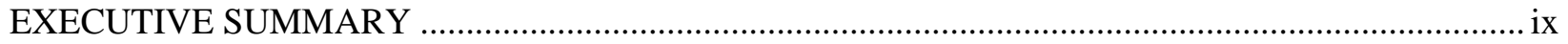

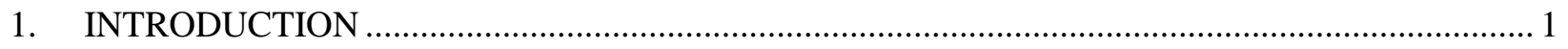

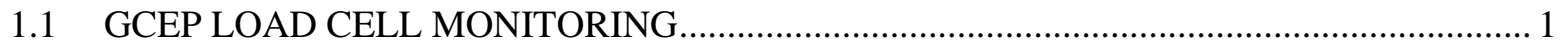

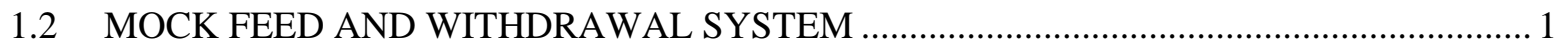

2. LOAD CELL MONITORING HARDWARE ................................................................... 2

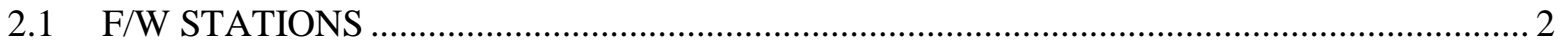

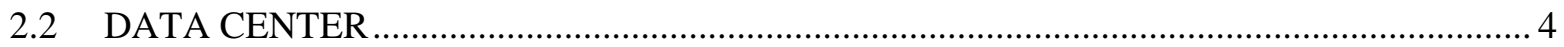

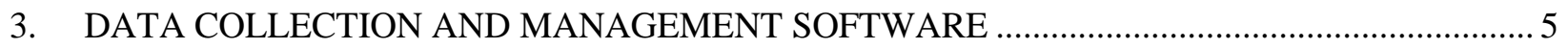

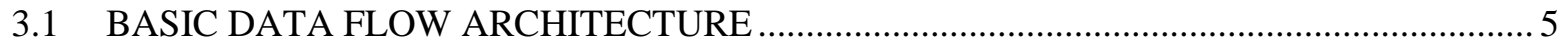

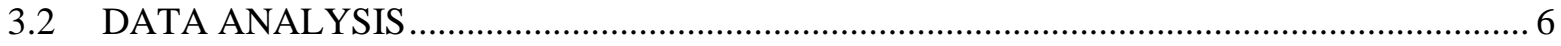

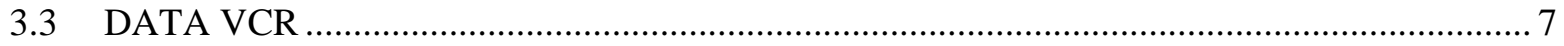

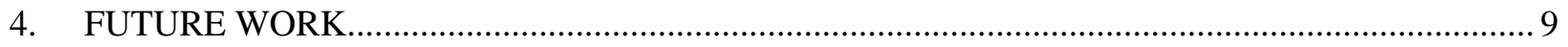

5. CONCLUSION

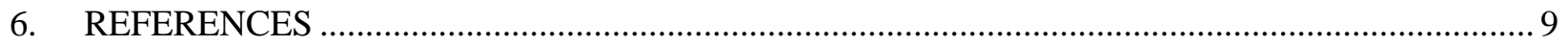





\section{LIST OF FIGURES}

Figure

Page

1 The Mock F\&W System was designed as a test bed for process-monitoring technologies. 1

2 A proof-of-concept load cell monitoring system developed on the Mock F\&W System leverages COTS hardware and software to provide a scalable system to collect, store, analyze, and visualize process-scale weight data.

3 Heavier, larger loads can be measured by using a junction box to connect multiple load

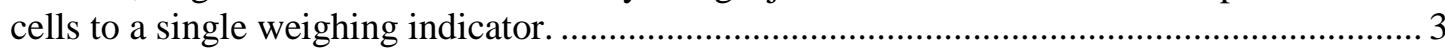

4 Five different types of weighing indicators that are commonly found in industry are collecting load cell data at the Mock F\&W system. 3 Industry-standard communication protocols and COTS software are integrated to provide a data flow architecture that is modular, interoperable, and scalable. A state diagram is used to represent the normal sequence of operational states for each F\&W station. .5

Data flow diagram.

A data VCR was developed by leveraging the interoperability of several COTS software packages..... 8

9

The data VCR leverages the interoperability of several software packages to play-back historical data in a visually compelling 3D representation of the Mock F\&W .8

\section{LIST OF TABLES}

\section{Table}

1 Weighing indicators installed and used to collect weight data in the Mock F\&W System 



\section{ACRONYMS}

3D three dimensional

COTS commercial off-the-shelf

DOE/NNSA Department of Energy National Nuclear Security Administration

F\&W feed and withdrawal

GCEP gas centrifuge enrichment plant

GUI graphical user interface

IAEA International Atomic Energy Agency

LAN local area network

OPC object linking and embedding for process control

OPC-UA OPC-unified architecture

ORNL Oak Ridge National Laboratory

PDI person days of inspection

PLC programmable logic controller

RFID radio frequency identification

TCP/IP transmission control protocol/internet protocol

$\mathrm{UF}_{6} \quad$ uranium hexafluoride

VCR videocassette recorder

WPF Windows Presentation Foundation 



\section{EXECUTIVE SUMMARY}

A proof-of-concept load cell monitoring system has been developed for the Mock Feed and Withdrawal (F\&W) System at Oak Ridge National Laboratory (ORNL). This system leverages industry-standard commercial off-the-shelf (COTS) hardware and software in a modular and scalable design.

The Mock F\&W System was designed to simulate operations at a uranium hexafluoride $\left(\mathrm{UF}_{6}\right)$ gas centrifuge enrichment plant $\mathrm{F} \& \mathrm{~W}$ area. It provides a test bed for process-monitoring technologies. Water, used as a surrogate for $\mathrm{UF}_{6}$, is pumped from three feed tanks, through a process surge tank, and is then cut between two tails tanks and three product tanks. The weight of the each tank is continuously monitored using a load cell monitoring system. In addition to the F\&W stations, large and small accountancy stations are monitored.

The Mock F\&W System allows ORNL to test and evaluate capabilities of industry-standard processmonitoring hardware and software. A variety of commonly used weighing indicators are connected to the load cells to monitor the weight at each station. These weighing indicators are representative of the types likely found in operating facilities.

A data center modeled after those currently used for international safeguards was installed to collect and manage the weight data. This data center provides a robust and flexible test bed for testing and developing software solutions. COTS software packages that leverage industry-standard communication protocols provide a data flow architecture that is modular, interoperable, and scalable.

One software package provides communication drivers to collect the raw weight data from the weighing indicators. A data historian is used to store the raw data. Custom in-house algorithms have been developed using MATLAB to analyze the raw historical data and to automatically identify process information. This information includes the number of cycles completed and the mass of material transferred from stations to the process. The process information identified by the analysis is stored in a Microsoft SQL Server database. Visualization concepts have been developed that display the analyzed process information alongside visually compelling plots and animations of the raw data.

The load cell monitoring system developed on the Mock F\&W System was designed as a proof of concept that could be scaled to a field trial at an operating facility. This system, built with industrystandard hardware and software, has allowed ORNL to develop capabilities that provide confidence in the ability to leverage existing operator load cell monitoring equipment with minimal impact on operations. The international safeguards community is evaluating the use of load cell monitoring as an additional safeguards measure; this system demonstrates a practical solution to collect, store, analyze, and visualize load cell weight data. 



\section{INTRODUCTION}

\subsection{GCEP LOAD CELL MONITORING}

As the number of countries deploying uranium enrichment technology and the separative capacities of individual plants increase, the ability of the International Atomic Energy Agency (IAEA) to effectively apply safeguards at these plants within a constrained budget is challenged. The three primary IAEA safeguards objectives for enrichment facilities are (1) detecting diversion of declared material, (2) detecting excess production of low-enriched uranium product, and (3) detecting the production of higher-than-declared enrichments - particularly highly enriched uranium.

New safeguards measures to continuously monitor load cells within feed and withdrawal (F\&W) stations are being investigated to provide a solution that can benefit both the plant operators and the inspectorates. Approaches are being considered that would leverage an operator's existing load cell monitoring equipment.

An acceptable means for sharing operator data from F\&W station load cells would benefit both the IAEA and the operators. The IAEA would benefit from increased effectiveness of achieving its safeguards objectives for gas-centrifuge enrichment plants (GCEPs), a possible reduction in on-site person days of inspection (PDIs), and a quicker resolution of safeguards-related discrepancies. Operators would benefit from reduced PDIs and therefore fewer required site escorts, a reduced number of cylinder reweighs and cylinder switch-over activities, and potentially reduced holding times for feed and product cylinders.

The U.S. Department of Energy National Nuclear Security Administration (DOE/NNSA) is funding research and development in new measures that could be applied to GCEPs to improve the effectiveness of safeguards and to increase efficiency by decreasing the burden on the operators and the inspectorates. Specifically, DOE/NNSA is investigating several measures associated with continuous monitoring of accountancy and F\&W station scales.

\subsection{MOCK FEED AND WITHDRAWAL SYSTEM}

Oak Ridge National Laboratory (ORNL) has designed and built the Mock F\&W System to test processmonitoring technologies (Fig. 1). The facility consists of three feed stations, three product stations, two tails stations, a "process" surge tank, a small accountancy station, and a large accountancy station. Water is used as a surrogate for uranium hexafluoride $\left(\mathrm{UF}_{6}\right)$ to simulate operations at a GCEP F\&W area. Each station consists of a load cell platform to support the tanks and a digital weighing indicator [1].

Water is pumped from the feed tanks, through the process surge tank and then into product and tails tanks. A valve controls the flow out of the process surge tank to the tails and product tanks. The valve has the option to be operated manually or by a proportional-integral-derivative controller. The cut between tails and product tanks is controlled by manual valves.

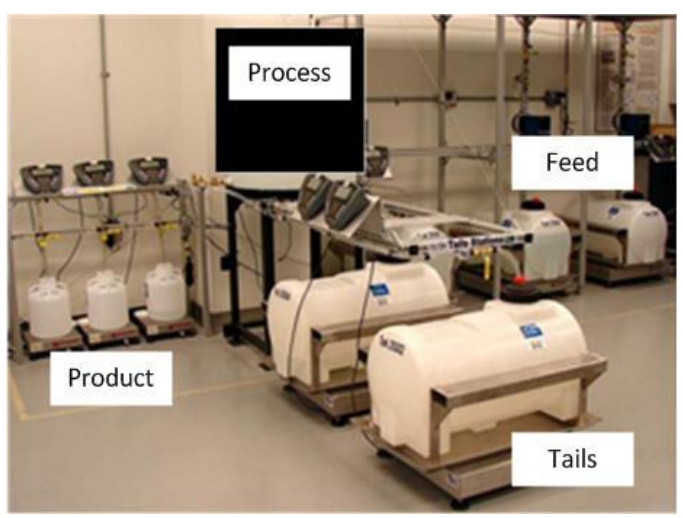

Fig. 1. The Mock F\&W System was designed as a test bed for process-monitoring technologies. Water, used as a surrogate for $\mathrm{UF}_{6}$, is pumped from feed stations, through a "process", and is cut between tails and product stations. Large and small accountancy stations (not shown) are also monitored. 
The Mock F\&W System has been used as a test bed for load cell monitoring technologies. The monitoring system that is demonstrated using the Mock F\&W System is considered a proof-of-concept for a field trial implementation.

The proof-of-concept load cell monitoring system, as shown in Fig. 2, utilizes commercial off-the-shelf (COTS) hardware and software wherever possible in a modular design that allows for individual components to be interchanged. The system is designed to be scalable to a size suitable for field trials at an operating GCEP. Industry-standard process-monitoring technologies are used to implement the load cell monitoring system. This system would have a minimal impact on operations at the facility while enhancing safeguards measures by providing a method for load cell data collection, storage, analysis, and visualization.

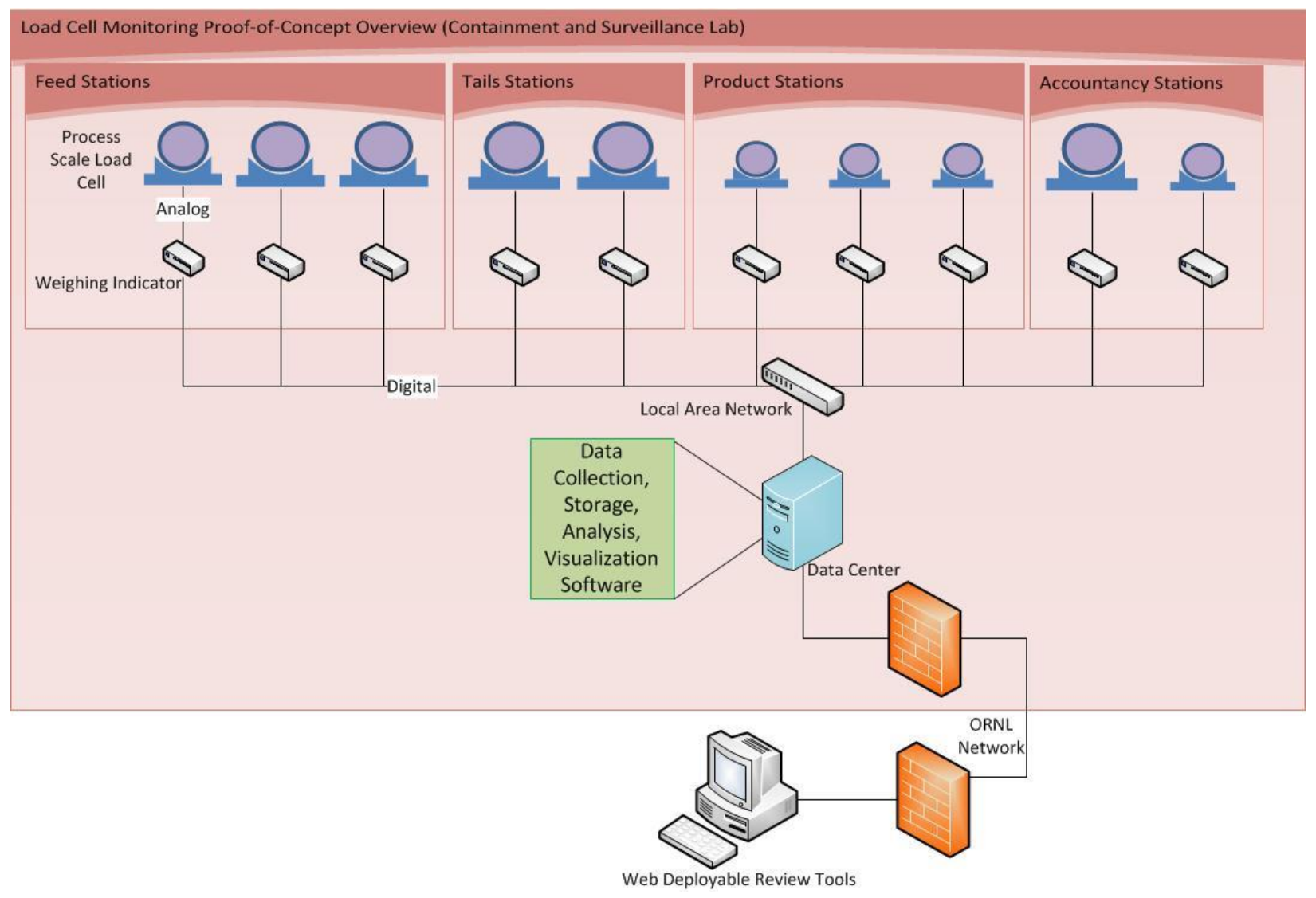

Fig. 2. A proof-of-concept load cell monitoring system developed on the Mock F\&W System leverages COTS hardware and software to provide a scalable system to collect, store, analyze, and visualize processscale weight data.

\section{LOAD CELL MONITORING HARDWARE}

\subsection{F/W STATIONS}

Many modern GCEPs have weighing systems integrated into the F\&W stations. These weighing systems typically consist of load cells connected to a weighing indicator to monitor $\mathrm{UF}_{6}$ cylinder weight. The weighing indicator supplies an excitation voltage to the load cell, which returns a signal voltage. The weighing indicator digitizes the signal voltage and translates it into a weight value. Most weighing indicators have a digital display to show the weight as well as an interface to connect to a computer or 
network. As shown in Fig. 3, often four load cells are bridged together in parallel using a junction box that is connected to a weighing indicator. This allows for heavier and larger loads to be weighed [2].

The F\&W stations on the mock system at ORNL were modeled after this design. However, because the loads being measured are smaller than those at an operating $\mathrm{F} \& \mathrm{~W}$, only one load cell is needed at each station.

Each feed and tails station uses a Mettler Toledo MT1260 load cell integrated into an

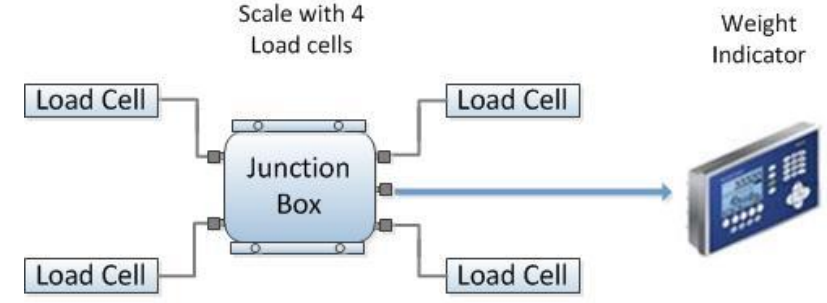

Fig. 3. Heavier, larger loads can be measured by using a junction box to connect multiple load cells to a single weighing indicator.

Ohaus Champ Square CQ250XL scale base. The capacity is $250 \mathrm{~kg}$ per station. Each product station uses a Mettler Toledo MT1241 load cell integrated into an Ohaus Champ Square CQ25R scale base. The capacity is $25 \mathrm{~kg}$ per station. The scale bases provide a weighing platform with adjustable feet to level the surface.

The Mock F\&W System allows ORNL to install weighing indicators that are commonly found in industry and to evaluate their capabilities. Five types of weighing indicators are currently installed. The capability to interface with these weighing indicators provides confidence that the data collection methods used for the Mock F\&W could be integrated into a field trial facility easily and with minimal impact on operations. Table 1 lists the weighing indicators currently utilized and the communication protocols that each supports.

Table 1. Weighing indicators installed and used to collect weight data in the Mock F\&W System

\begin{tabular}{lll}
\hline \multicolumn{1}{c}{ Manufacturer } & \multicolumn{1}{c}{ Model } & \multicolumn{1}{c}{ Communication protocols } \\
\hline Syrinx & SD2100 & Serial RS-232, RS-485; Modbus RTU; Modbus TCP; PROFIBUS \\
& & Serial RS-232, RS-422, RS-485; Allen Bradley RIO; DeviceNet; \\
Mettler Toledo & IND560 & PROFIBUS DP; EtherNet/IP; Modbus TCP \\
Ohaus & CD-33 & Serial RS-232 \\
Wohwa & GCU-64 & Serial RS-232, RS-422, RS-485 \\
Scaime & IPE 50 & Serial RS-232, RS-485; PROFIBUS \\
\hline
\end{tabular}

ORNL is evaluating several methods to transfer weight data from the weighing indicators to the data collection system. All of the methods use either RS-232 or Modbus TCP as the communication protocol. These methods are shown in Fig. 4 (from left to right):

- An Ohaus CD-33 is connected using an RS-232 connection to an Allen Bradley programmable logic controller (PLC).

- Several Ohaus CD-33s are connected using an RS-232 connection to Perle serial-to-Ethernet bridges.

- A Mettler Toledo IND-560 uses both an RS-232 connection to a Moxa serial-to-Ethernet bridge and the Modbus TCP protocol. 
- A Wowha, Scaime, and Syrinx are connected using an RS-232 connection to a Moxa serial-toEthernet bridge.

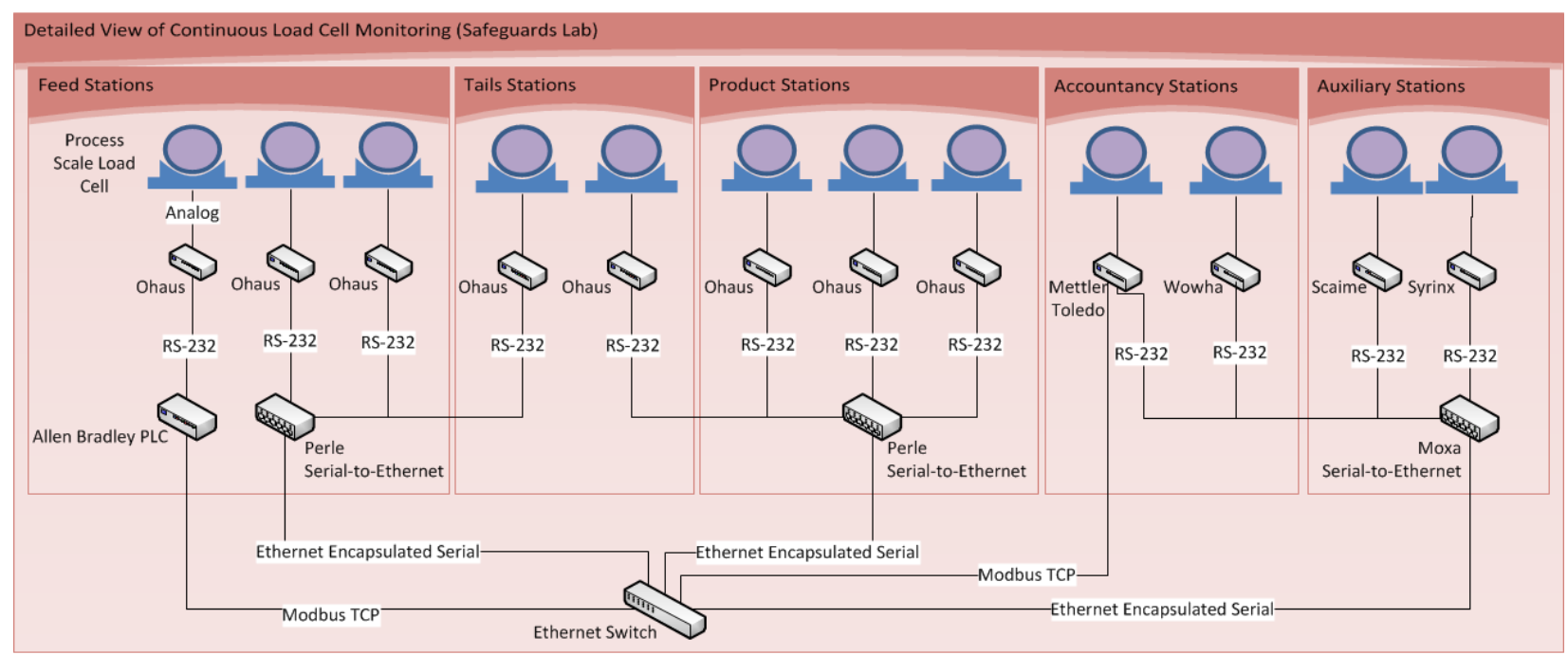

Fig. 4. Five different types of weighing indicators that are commonly found in industry are collecting load cell data at the Mock F\&W system. Two different communication protocols are used to transfer data from the weighing indicators: Serial RS-232 and Modbus TCP.

ORNL is using two types of serial to Ethernet bridges: Moxa nPort 6450 and Perle IOLAN STS49. Each serial-to-Ethernet bridge has four separate serial ports, so each can interface with up to four weighing indicators. Each bridge has one Ethernet port and occupies one address on the local area network (LAN).

The Perle and Moxa serial-to-Ethernet bridges use Ethernet encapsulation to transfer serial data over Ethernet. The RS-232 data are transferred from each weighing indicator to the serial-to-Ethernet bridge, where they are encapsulated into transmission control protocol/internet protocol (TCP/IP) packets. Once encapsulated in TCP/IP packets, the data are transferred from the serial-to-Ethernet bridge through the LAN. The Moxa has the additional capabilities of transmitting data using a secure sockets layer or a secure shell for added security.

The Mettler Toledo weighing indicator can transfer data using Modbus TCP or serial. Modbus TCP uses TCP/IP data packets directly. No additional equipment, such as the serial-to-Ethernet bridge, is needed. The Mettler Toledo weighing indicator itself occupies an address on the LAN.

ORNL is evaluating using a PLC to transfer data to the data collection system. An Allen Bradley MicroLogix 1400 has been programmed to interface with one of the Ohaus weighing indicators via RS232. The Allen Bradley PLC is connected to the LAN and transfers data using Modbus TCP.

\subsection{DATA CENTER}

A flexible and robust data center has been assembled to collect and manage data from the weighing indicators. The data center is modeled after those currently used for international safeguards. At the heart of the data center are three Hewlett Packard blade servers running Windows Server 2008 R2. The servers share power, cooling, storage, and networking. Power is provided by an uninterruptible power supply.

Storage is provided by a storage area network. This type of storage allows for scalable disk space to be allocated to each server. It also allows for high availability by implementing virtualization. Individual 
tasks associated with handling the data (e.g., collecting, storing, analyzing, visualizing) are all performed on individual virtual machines that reside on any three of the physical blade servers. If one physical server fails, the virtual machines automatically switch over to a different physical sever without stopping operations. This provides a more robust and flexible system for testing software components.

\section{DATA COLLECTION AND MANAGEMENT SOFTWARE}

\subsection{BASIC DATA FLOW ARCHITECTURE}

COTS software packages have been implemented at the data center to manage the weight data. These packages use industry-standard communication protocols to provide a data flow architecture that is modular, interoperable, and scalable. Figure 5 shows the data flow from the weighing indicator through the various packages.

Kepware KepserverEx is the communication driver software at the data center used to collect the weight data. This software has hundreds of drivers that allow it to communicate with various commonly used process-monitoring devices. Two of the drivers allow it to communicate via Ethernet encapsulated serial and Modbus TCP. KepserverEX collects and translates the data to object linking and embedding for process control (OPC) and OPC unified architecture (OPC-UA) communication protocols.

\section{Canary Labs Enterprise Historian stores} the weight data it receives from KepserverEX. Enterprise Historian can receive data from more than one million individual data sources (tags) and can store up to 3.6 million updates per second. The space required to store data using this historian is about 2.5 gigabytes per month for 100 tags updated every second (assuming Real8 datatype) [3]. Once in the historian, data can be retrieved using either OPC or OPC-UA.

MATLAB was used to develop custom in-house analysis algorithms that retrieve the historical weight data from Enterprise Historian and automatically identify processed cycle information. The analysis algorithms are discussed in more detail in Sect. 3.2, "Data Analysis."

SQL Server is used to store the information that is identified by the analysis. MATLAB and SQL Server communicate using a Java database connectivity driver (JDBC).

SQL Server Reporting Services is used to display the information from the analysis. These reports allow the user to "drill down" from a high level and view process information at individual F\&W areas and stations. For instance, a user may see a list of all the completed cycles (cylinders processed) and the 
total weight transferred at an entire facility during a selected time period. From there, the user can drill down to a particular F\&W area to see the completed cycles and the weight transferred for just that area, or even further to see the completed cycles and weight transferred at a single station.

Iconics Genesis64 is used to display raw data in a visually compelling manner. Historical and live data can be plotted to view trends and cycles. Three-dimensional (3D) animations display current process data and play back historical data.

A Windows Presentation Foundation (WPF) application was developed as a graphical user interface (GUI) that displays historical plots, compelling 3D animations, and analysis results. The WPF pulls together visualizations from SQL Server Reporting Services and Iconics Genesis64.

\subsection{DATA ANALYSIS}

A MATLAB script has been developed to analyze load cell data and to identify F\&W cycles at each station. The objectives of the analysis are to (1) count the number of cycles completed during a given time period and (2) calculate the mass transferred between the tanks and the process.

The analysis uses a rules-based method. Data are collected from the data historian for a user-defined time span. Every data point in the time span is then compared to a set of mutually exclusive rules. The rules define the status of the load cell as one of four operational states.

The rules implemented for analysis on the Mock F\&W System represent the operational states that occur during normal operations at a GCEP F\&W station:

- Vacant - nothing on the scale

- Full - the load cell is occupied with a full cylinder

- Empty - the load cell is occupied with an empty cylinder

- Filling or Draining - the load cell is occupied with a cylinder that is either being filled or drained

Each rule is represented by four limits: (1) maximum weight, (2) minimum weight, (3) maximum rate of change, and (4) minimum rate of change. If a data point falls within all of these limits, it is said to be in the "operational state" represented by that rule. An example of the rule set used to define the "operational state" for a tails filling station at the Mock F\&W is shown in Table 2.

\begin{tabular}{|c|c|c|c|c|}
\hline \multirow{2}{*}{ Operational state } & \multicolumn{2}{|c|}{ Weight (kg) } & \multicolumn{2}{|c|}{ Rate of change $(\mathrm{kg} / \mathrm{sec})$} \\
\hline & Max & Min & Max & Min \\
\hline Station vacant & 0.5 & -0.5 & 0.009 & -0.009 \\
\hline Empty cylinder & 50 & 0.5 & 0.009 & -0.009 \\
\hline Cylinder filling & 200 & 0.5 & .075 & 0.009 \\
\hline Full cylinder & 200 & 125 & 0.009 & -.009 \\
\hline
\end{tabular}

The sequence of operational states is compared to a state diagram that represents normal operation for that station. A warning is given in MATLAB if the sequence of operational states does not follow the normal operations defined by the state diagram. 
The state diagram also includes information about which state represents the beginning of a cycle, the start weight, and the end weight, as depicted in Fig. 6 [4].

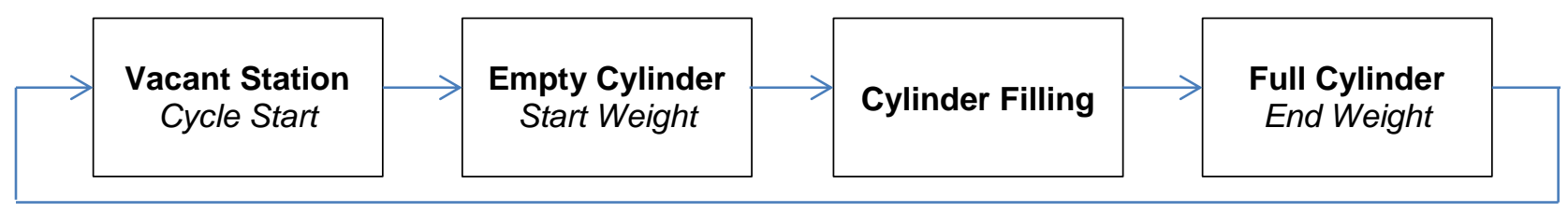

Fig. 6. A state diagram is used to represent the normal sequence of operational states for each $F \& W$ station. This state diagram represents a tails or product filling station.

By comparing the sequence of operational states of the load cell data to the state diagram, the algorithm identifies complete cycles, start weights, and end weights.

An SQL database holds metadata about the facility. The metadata includes the number of stations to be analyzed, the types of stations (feed, product, tails), the rules used to perform the analysis at each station, and the location of the raw weight data (i.e., the network address of the historical data in the data center).

The MATLAB analysis script was written such that with minimal changes it could be scaled from the Mock F\&W to a full-scale facility with different operating parameters. The analysis rules, the metadata about the F\&W stations, and the weight data are all separate from the analysis algorithms. This information is retrieved automatically by the analysis script when it is executed. Separating this information from the analysis allows the same algorithms to be applied to different facilities with different operating parameters.

When the analysis script is executed, MATLAB first reads the facility F\&W information from an SQL Server database table. MATLAB then picks up the historical weight data from Canary Labs Historian for a particular F\&W station as specified in the database. The analysis is performed, the results are written back out to an SQL Server database table, and the algorithm proceeds to the next F\&W station. A diagram of this data flow is shown in Fig. 7.

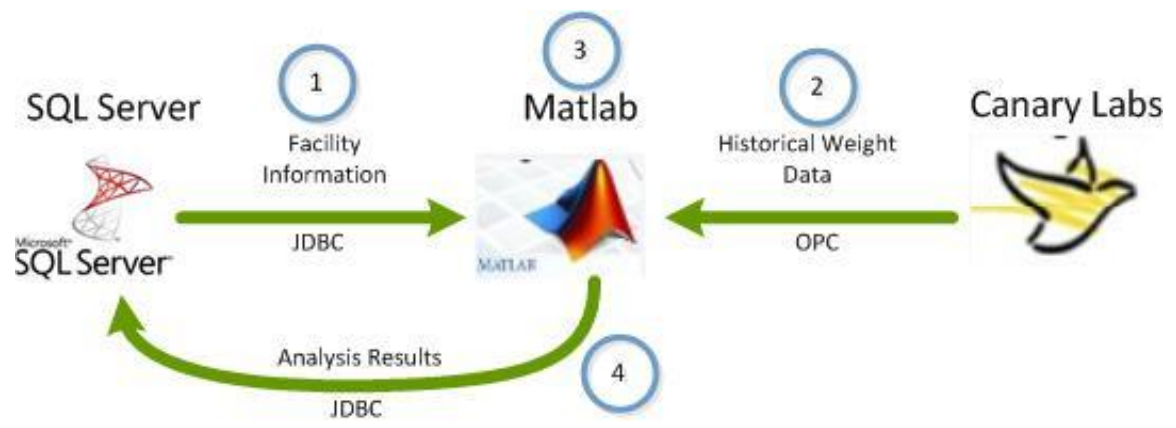

Fig. 7. Data flow diagram. (1) A MALTLAB analysis script retrieves the information needed to perform the analysis from an SQL Server. (2) MATLAB retrieves the raw weight data from Canary Labs Enterprise Historian. (3) Analysis is performed. (4) The analysis results are written back to an SQL Server.

\subsection{DATA VCR}

A historical data playback GUI, referred to as "the VCR" (whose controls, including fast-forward, rewind, start, stop, and pause are similar to those on a videocassette recorder) is made possible by leveraging the interoperability of several of the software packages. 
The VCR GUI is built using Iconics Genesis64. This interface animates operations at the F\&W stations in a 3D model. The weight data are used to illustrate tanks as they fill or drain, where green represents the full portion and red represents the empty portion of each tank. The actual weight values are also listed on the screen as they change. The user enters the start and end time of the operations to be viewed. Figure 8 shows a screenshot of the VCR GUI with two feed, two tails, and three product stations occupied; the third feed station is vacant.

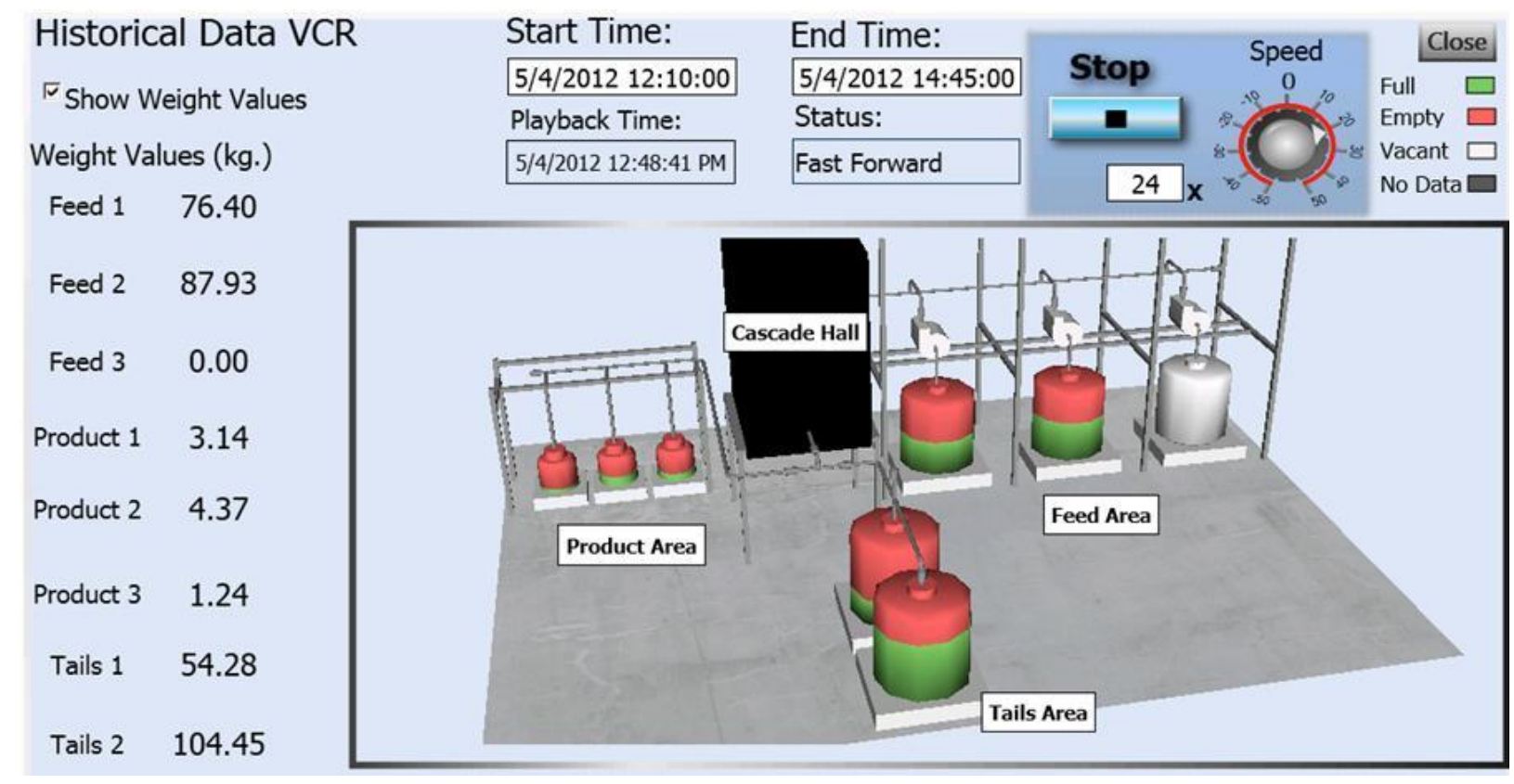

Fig. 8. A data VCR was developed by leveraging the interoperability of several COTS software packages. This VCR allows "playback" of weight data in visually compelling representations of the Mock F\&W System.

MATLAB, KepseverEX, and Canary Labs Enterprise Historian work together to run the VCR in the background. KepserverEX and Canary Labs Enterprise Historian both operate as Windows Services. A MATLAB script was compiled to an executable file. The file is scheduled to execute on Windows startup. Once executed, the file runs continuously as a background process.

Commands entered by the user in the VCR GUI are received by KepseverEX. KepserverEX passes them to MATLAB. MATLAB processes the commands, retrieves the required data from Canary Labs Enterprise Historian, and passes the data back to KepserverEX. KepserverEX passes the data to the VCR GUI, which displays the data. Figure 9 shows a diagram of the data flow for the VCR.

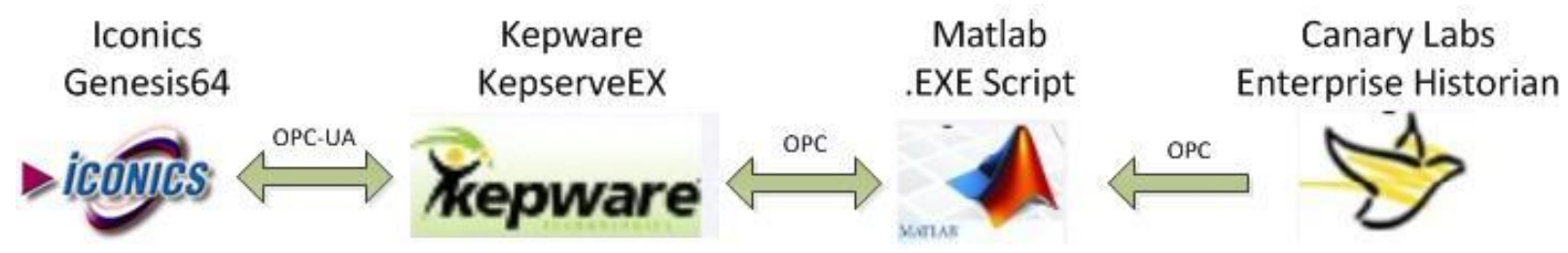

Fig. 9. The data VCR leverages the interoperability of several software packages to play-back historical data in a visually compelling 3D representation of the Mock F\&W. 


\section{FUTURE WORK}

ORNL is continuing to add additional hardware and software to the Mock F\&W System.

Work has started to equip the Mock F\&W facility with a radio frequency identification (RFID) system that could help monitor cylinders as they move through a facility. COTS RFID hardware and software are used to record the events as tanks are positioned at different stations. In the future, this information may be integrated with the load cell data or other information.

Surveillance cameras have also been installed at the Mock F\&W System. COTS software is being used to integrate video surveillance data with the RFID data to add confidence about weighing operations.

ORNL is also developing methods for splitting load cell data between the operator's system and a safeguards network. This would allow the safeguards network and data center to use existing operator load cell monitoring equipment to collect weight data independently from the facility operator.

In addition, work is continuing to evaluate the most useful ways to visualize and present data.

\section{CONCLUSION}

The Mock F\&W System at ORNL has provided an effective test bed for testing process-monitoring technologies. The load cell monitoring system implemented at the Mock F\&W has allowed ORNL to develop capabilities and expertise with hardware and software that are commonly found in the processmonitoring industry.

A prototype load cell monitoring system developed for the Mock F\&W System provides a scalable, interoperable solution for load cell data to be collected, stored, analyzed, and visualized. The system uses a modular approach that implements industry-standard COTS hardware and software wherever possible.

ORNL is continuing to enhance methods to analyze and visualize load cell data. Analysis algorithms automatically identify processed cycle information such as the number of cycles completed and the mass transferred from each station. A GUI presents data visualizations in a user-friendly tabular format, in plots, and in 3D animations.

This proof-of-concept load cell monitoring system shows that methods for leveraging existing operator's load cell monitoring equipment using commercial hardware and software supplemented by minimal custom software could provide a practical means for an additional safeguards measure.

\section{REFERENCES}

1. Alan M. Krichinsky et al., A Mock $U F_{6}$ Feed and Withdrawal System for Testing Safeguards Monitoring Systems and Strategies Intended for Nuclear Fuel Enrichment and Processing Plants, ORNL/TM-2009/229; Oak Ridge National Laboratory, Oak Ridge, Tennessee, 2009.

2. J.R. Garner et al., "Leveraging the Intrinsic Features of Commercial Off-The-Shelf Weighing Indicators to Build Confidence in International Safeguards Measures," Proceedings of the INMM Annual Meeting, 2012.

3. Canary Laboratories, Canary Enterprise Historian Specification, 2011. 
4. R. S. Snow et al., "Applying Process Monitoring at Gas Centrifuge Enrichment Plants Using Commercial Off-The-Shelf Industrial Control Products," Proceedings of the INMM Annual Meeting, 2012. 